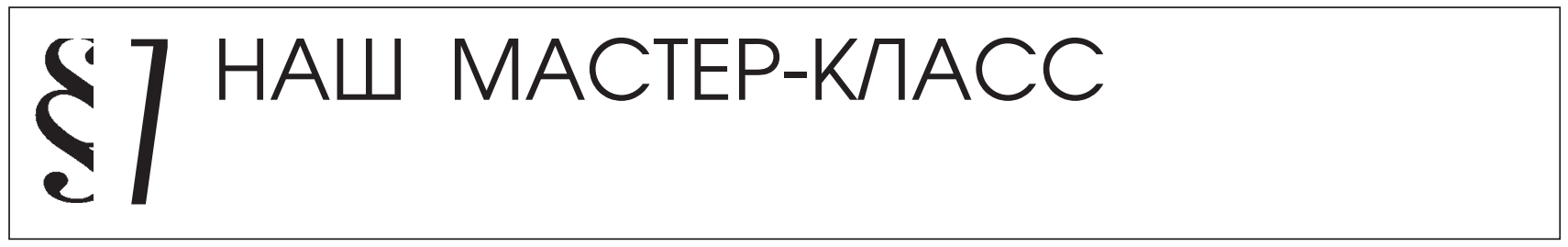

Нестеров А.A.

\title{
МЕТОДИКА ОЦЕНКИ ПРОИЗВОДСТВЕННОЙ И ИНФОРМАЦИОННОЙ СОСТАВЛЯЮЩИХ ИННОВАЦИОННОЙ СРЕДЫ ЭКОНОМИЧЕСКИХ СИСТЕМ
}

Аннотация: Статья содержит методику оценки уровня развития составляющих инновационной среды экономических систем, уровень развития технологической инфраструктуры, сравнительный анализ внутренней и внешней составляющих инновационной среды. Рассмотрен перечень факторов, определяющих структуру производственной инфраструктуры и информационной составляющей экономических систем. Приведен пример оченки основных составляющих технологической инфраструктуры экономических систем уровня федеральных округов, рейтинговые оченки развития технологической инфраструктуры федеральных округов по статистическим данным за 2010 год, приведень рейтинги производственной и информаџионной составляющих инновачионной среды федеральных округов.

Review: The article contains the method for the evaluation of the development level of the components of the innovative environment of economic systems, level of development of technological infrastructures, comparative analysis of inner and outer elements of innovative environment. The author provides a list of factors defining structure of an industrial infrastructure and information elements of economic systems. The author also provides an example of evaluation of the main components of technological infrastructure of economic system at the federal district level, as well as rating evaluation of development of the technological infrastructure of federal districts in accordance with the statistical data for 2010, he provides the ratings of industrial and information elements of the innovation environments of federal districts.

Ключевые слова: Экономика, методика, уровень, рейтинг, оченка, развитие, факторы, инфраструктура, инновачия, среда

Keywords: economics, method, level, rating, evaluation, development, factors, infrastructure, innovation, environment.

охраняющийся уровень дифференциации социально-экономического развития субъектов Российской Федерации ведет к замедлению экономического развития, кроме того, именно от инновационной активности и инновационной восприимчивости отраслевых и региональных экономик зависит стратегическая конкурентоспособность России в мировой экономике. В условиях интенсификации развития экономики знаний, инновационный вариант развития российской экономики является безальтернативным. Актуальность инновационного развития экономических систем продиктована как внутренними проблемами, так и системой внешних экономических взаимодействий. Использование новейших 
достижений в научно-технической и технологической сфере промышленными предприятиями возможно при хорошо налаженной системе разработки, внедрения и коммерциализации инновационной продукции [1]. А это подразумевает наличие эффективно функционирующей технологической инфраструктуры. Каждое предприятие, ведущее активное внедрение инноваций в своем производстве, должно принять важное стратегическое решение: приобретать инновации на стороне или разрабатывать самостоятельно.

Основным этапом работы при принятии решения об инвестировании в инновационный проект, выборе объекта, выступает процедура оценки развития инновационной среды экономической системы; в то же время, подобная оценка является сложной задачей приведения в сопоставимый вид результатов выявления действия отдельных факторов и расчета выборочных показателей. Главное условие использования полученной информации - ее систематизация и приведение к интегральному показателю.

Интегральный показатель уровня развития инновационной среды состоит из суммы показателей оценки двух основных подсистем - технологической инфраструктуры и человеческого капитала (рис. 1). При этом если подсистема поддержки инноваций достаточно однородна для всей России, то инфраструктура инновационной деятельности в каждой отрасли, на каждом предприятии имеет свои особенности. Это закономерно и оправданно, поскольку отдача от эксплуатации инновационной инфраструктуры может быть высока, и менеджмент заинтересован в ее развитии.

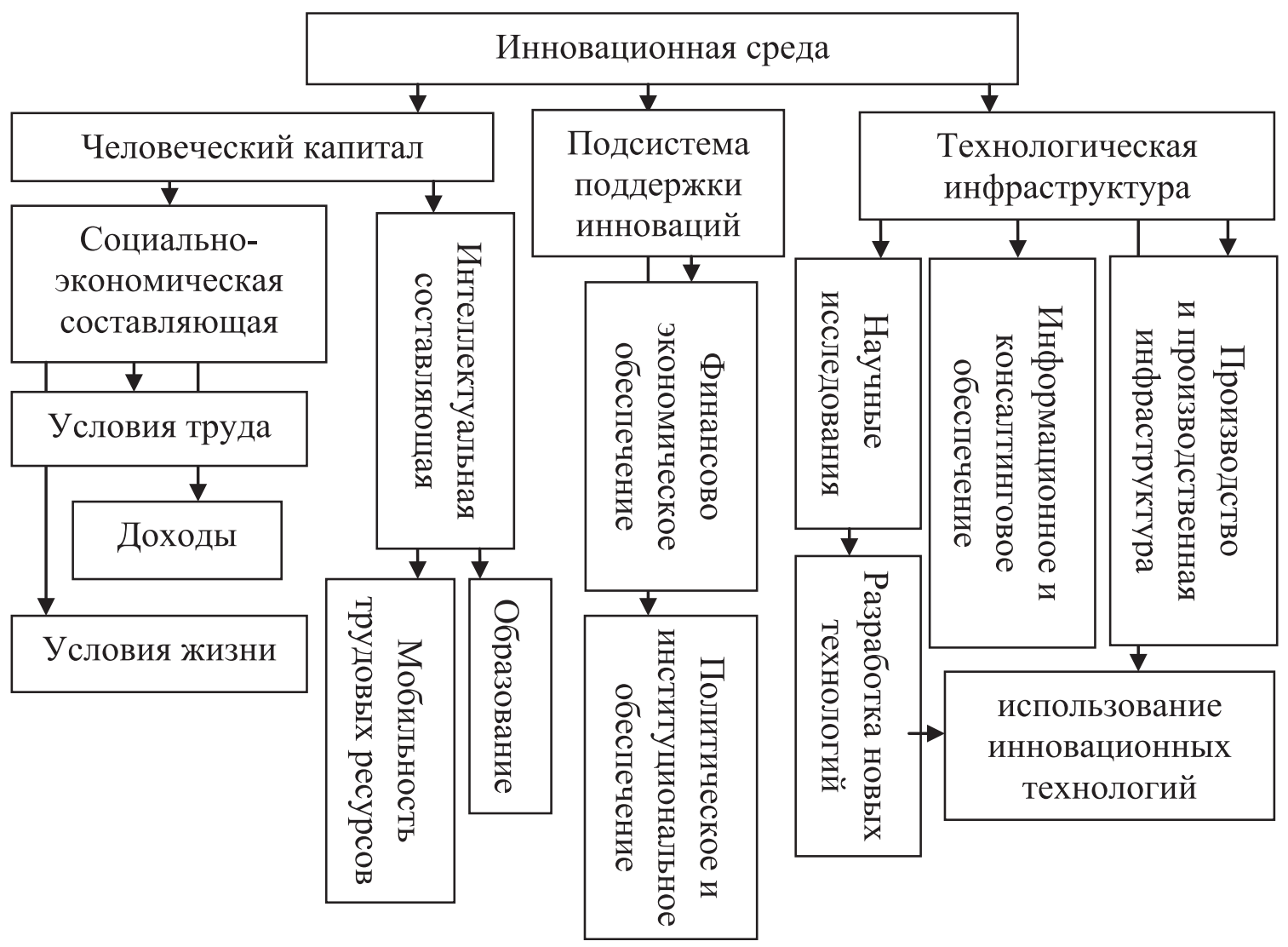

Рис. 1. Структура инновационной среды экономических систем 
DOI: $10.7256 / 1812-8688.2013 .8 .6617$

При цитировании этой статьи сноска на доі обязательна

\section{Налоги и налогообложение - №8(110) 2013}

Технологическая инфраструктура экономических систем проявляется не только в масштабах, но и качестве их материально технической базы, в техническом уровне средств труда [2]. Под технологическим уровнем экономических систем понимается степень технологической прогрессивности оборудования и технологии, включая качество используемого сырья и материалов, уровень организации и управления, качество выпускаемой продукции, т. е.
Технологическая инфраструктура инновационной деятельности - совокупность субъектов инновационной деятельности, обеспечивающих условия, необходимые для производства инновационных изделий и услуг. Факторное пространство, определяющее технологическую инфраструктуру экономических систем, состоит из трех составляющих - производственного, исследовательского и информационного обеспечения (рис. 2).

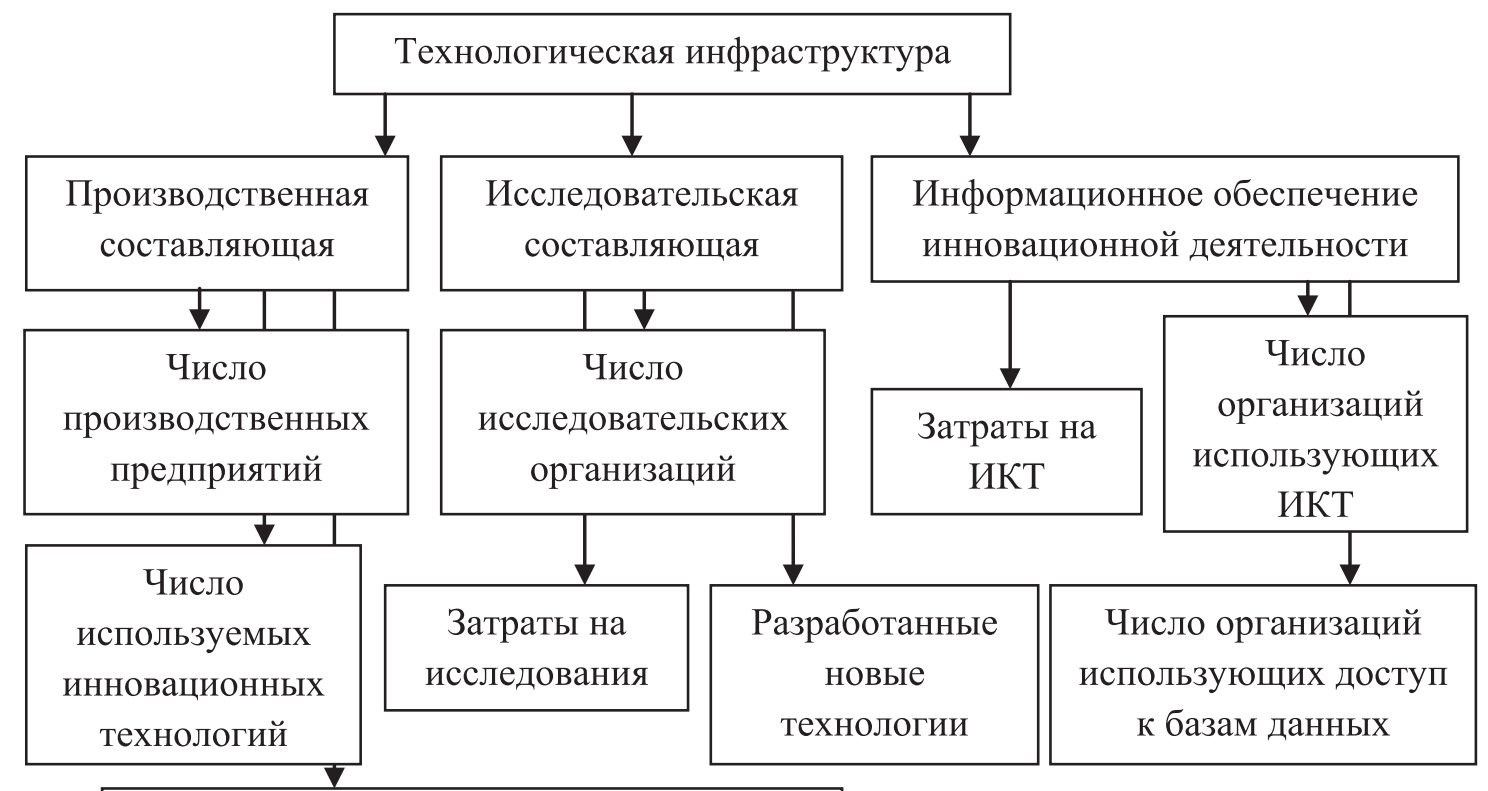

Инновационная активность предприятий

Рис. 2. Схема управления развитием технологической инфраструктурой экономических систем

трактуется в расширительном смысле как уровень развития производительных сил. Определение технологического уровня предполагает оценку технологической оснащенности производства и труда; технико-экономического уровня оборудования и технологии, уровень механизации и автоматизации производственных процессов и управления. Повышение технологического уровня находит свое выражение в повышении эффективности производства [3].
Производственная составляющая (производственная инфраструктура) - это совокупность производственных организаций использующие и производящие инновационные технологии. Производственная составляющая технологической инфраструктуры определяется числом производственных предприятий, входящих в рассматриваемую экономическую систему, инновационной активностью этих предприятий и числом используемых инновационных технологий. 
Составляющая научно-исследовательской инфраструктуры включает в себя следующие основные компоненты, имеющие различное функциональное назначение: число исследовательских организаций, уровень затрат на исследования и разработку инновационной технологий и продуктов, итоговое число разработанных инновационных технологий. Так, число исследовательских организаций и затраты на научные исследования определяют исследовательскую базу инфраструктуры, которая влияет на масштабы и темпы инновационной деятельности [4].

Следующая компонента инфраструктурной составляющей - информационный peсурс. С развитием общества запасы информационного ресурса постоянно увеличиваются и являются движущей силой инновационной среды. В этой области существует достаточно разветвленная сеть организаций, включающая территориальную систему государственных центров научнотехнической информации, структуры поддерживающие малый бизнес, информационные сети. Основная информация, которая может оказывать влияние на решение задач инновационного развития и по которой существует значительный дефицит, связана с информацией о рынках. Еще одна группа вопросов информационного обеспечения инновационной деятельности связана с доведением информации о новых разработках до потенциальных пользователей, организация консультаций по их использованию. Частично данная проблема может быть решена благодаря созданию сети информационно-аналитических центров по приоритетным направлениям развития науки и техники, а также по инновационной тематике. Оценить уровень информационного обеспечения инновационной деятельности экономической системы возможно по основным параметрам - затраты на информационные технологии, число организаций использующие информационные технологии и число организаций использующих доступ к глобальным базам данных.

В качестве примера рассмотрим методику оценки основных составляющих технологической инфраструктуры экономических систем уровня федеральных округов. При ее разработке мы исходили из того, что наличествующие данные не могут рассматриваться совместно, поскольку они существенно зависят от размера экономической системы, числа экономически активного населения, уровня взаимосвязи экономических систем различных округов, при этом для их сравнительного анализа необходимо согласование, рассмотрение относительных, безразмерных величин и нормирование их значений.

Для построения сравнительной рейтинговой оценки составной части инновационной среды экономических систем - технологической инфраструктуры - могут быть использованы различные алгоритмы. Для решения данной проблемы при расчете интегрального показателя уровня развития инновационной среды необходимо использовать минимальный набор показателей одного уровня с максимальным охватом значимых факторов. Определим технологическую инфраструктуру инновационной среды экономической системы как совокупность объектов инновационной деятельности и взаимосвязей между ними, которые производят новые знания и новшества, преобразуют их в новые продукты и услуги, обеспечивают их производство, распространение и потребление. Необходимость 
DOI: $10.7256 / 1812-8688.2013 .8 .6617$

При цитировании этой статьи сноска на dоі обязательна

\section{Налоги и налогообложение - №8(110) 2013}

оценивания, мониторинга и управления технологической инфраструктурой, как следствие, параметрами ответственными за ее развитие, очевидна и требует использования эффективных методов их измерения.

Учитывая многофакторный характер экономических явлений и процессов в развитии инновационной среды экономических систем, а также преимущественно их качественный характер, в настоящее время все более популярным становится использование в методике оценивания системы рейтингов. Рейтинги позволяют через количественные оценки в агрегированном виде представить качественное состояние изучаемых объектов, более того, рейтинговая система позволяет оценивать состояние не одного выделенного объекта, а определить положение экономической системы во внешнем окружении. Главной целью составления рейтинговых оценок является ориентация потенциального инвестора на объект путем предоставления ему минимального уровня исчерпывающей и сопоставимой информации о потенциальных возможностях вложения капитала посредством определения интегрального показателя.

Рейтинг уровня развития инновационной среды экономической системы представляет собой численное значение, ранг или балльное значение, присвоенное объекту инвестиций. В общем случае показателей может насчитываться достаточно большое количество. При большом числе показателей между ними, как правило, существуют значимые корреляционные связи, которые свидетельствуют об избыточности системы показателей. Кроме того, все показатели имеют некоторые погрешности, которые носят случайный характер. Сам по себе процесс оценки является непростым, так как, с одной стороны, необходимо учитывать как можно больше существенных факторов, с другой, - это приводит к трудностям с оперативностью использования методики, а также потребности во введении весовых коэффициентов, влияющих на конечный результат.

Предлагаемая нами методика содержит последовательность операций, позволяющих выделить систему факторов, ответственных за формирование параметров, определяющих уровень развития технологической инфраструктуры рассматриваемой экономической системы. Поученные результаты суммируются, в результате чего определяется уровень технологической инфраструктуры экономической системы относительно внешнего окружения по основным выделенным показателям. Для определения интегральной оценки предлагается использовать две формы вычисления результирующего индекса - мультипликативную и аддитивную:

$$
\begin{gathered}
D_{\text {mult }}=\prod_{i=1}^{i=n} d_{i}^{x_{i}} \\
D_{\text {add }}=\sum_{i=1}^{i=n} x_{i} \times d_{i} .
\end{gathered}
$$

Здесь $D_{\text {mult }}$ - мультипликативная оценка; $D_{a d d}$ - аддитивная оценка; $d_{i}$ - рейтинги рассматриваемых факторов; $x_{i}-$ весовой коэффициент фактора $i$. 
Согласно теории измерений, формула (1) дает жесткую - пессимистическую оценку регионального индекса миграционной привлекательности, формула (2) более мягкую, оптимистическую.

Алгоритм оценки технологической инфраструктуры рассмотрим на примере экономических систем уровня федеральных округов. Оценка интегрального значения рейтинга каждого из федеральных округов и их ранжирование позволяет оценить как уровень развития внутренней составляющей, так и рейтинги внешнего окружения. Для оценки технологической инфраструктуры принимаем показатели, приводимые в изданиях Росстата. Поскольку для сравнения различных показателей необходимо оперировать относительными и нормированными значениями, в качестве составляющих рейтинга принимаем индикаторы, рассчитанные по формуле
$(1,27)$, Приволжском $(1,22)$ и Центральном федеральных округах $(1,06)$, а минимальная - в Северо-Кавказском округе $(0,48)$.

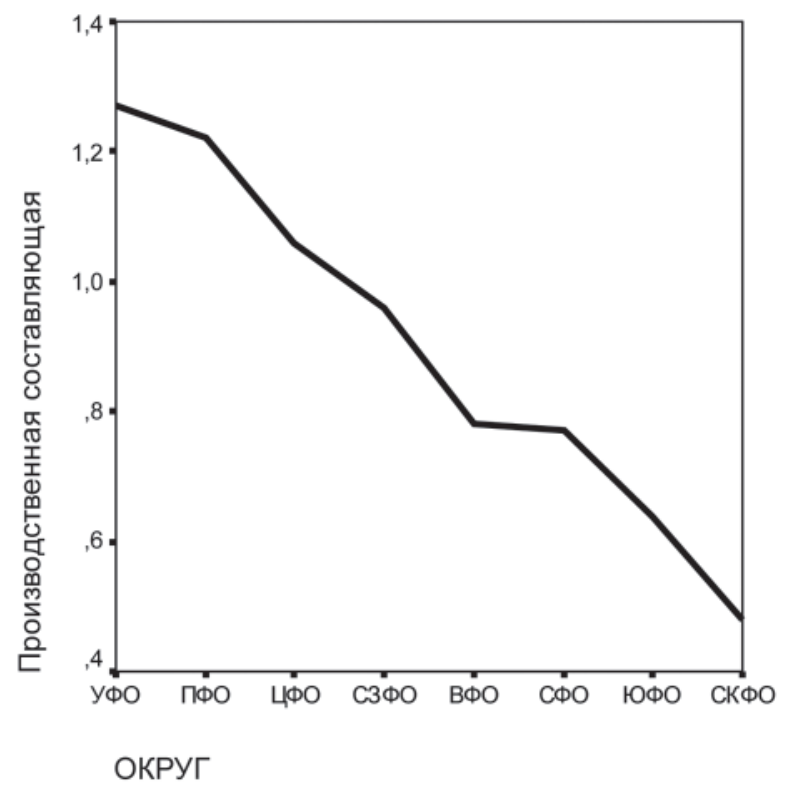

Рис. 3. Распределение по федеральньм округам приведенного коэффициента производственной составляющей инновационной средь

$$
d_{i}=\frac{P_{i}}{P_{\text {среднее }}},
$$

где $d_{i}$ - значение индикатора $i$-ого федерального округа; $P_{i}-$ приведенное значение (из расчета на 10000 человек экономически активного населения) показателя для $i$-ого федерального округа; $P_{\text {среднее }}-$ среднее значение показателя по России.

В качестве примера приведем рейтинговые оценки развития технологической инфраструктуры федеральных округов по статистическим данным за 2010 год - рис. 3-6.

На рис. 3 приведен график ранжированных значений коэффициента производственной составляющей. При разбросе значений более чем в 2,5 раза максимальные величины уровня развития производственной составляющей в 2010 г. наблюдались в Уральском
Аналогичным образом, рассмотрим распределение по федеральным округам уровня развития исследовательской составляющей инновационной среды. Результирующая величина, определяющая уровень исследовательской составляющей инновационной среды, приведена на рис. 4. 


\section{Налоги и налогообложение - №8(110) 2013}

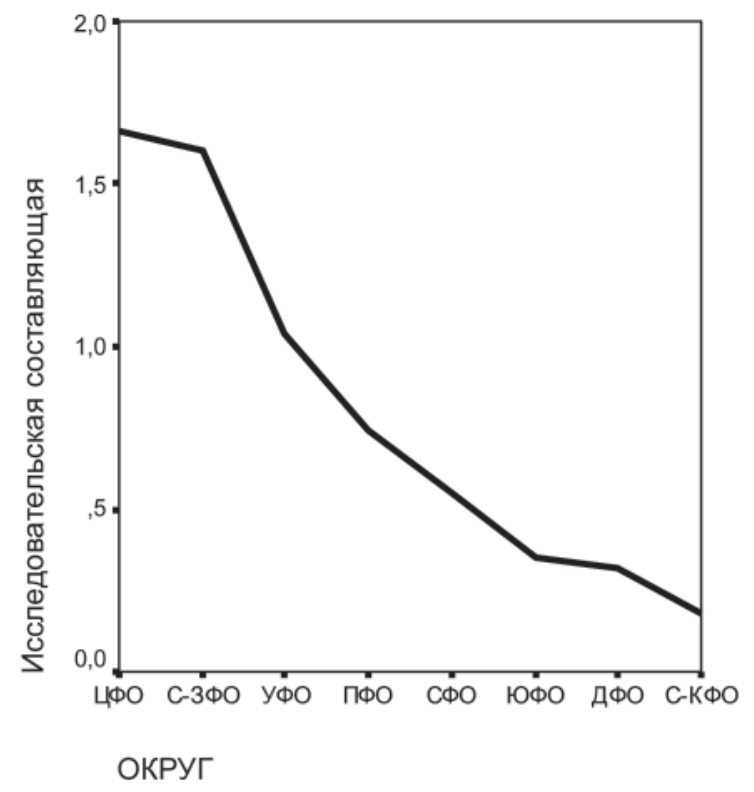

Рис. 4. Распределение по федеральным округам приведенного коэффичиента, определяющего исследовательскую составляюшую

Явно выделяются лидирующие федеральных округа - Центральный и СевероЗападный, при трех аутсайдерах - СевероКавказский, Дальневосточный и Южный. Десятикратный разброс приведенного коэффициента исследовательской составляющей говорит о существенной неравномерности в территориальном развитии исследовательской составляющей.

Распределение по федеральным округам информационной составляющей представлено на рис. 5. Видно, что информационная составляющая имеет максимальное значение для Дальневосточного $(1,26)$ и Уральского $(1,24)$ федеральных округов, а минимальное - со значительным отрывом - для СевероКавказского $(0,35)$ федерального округа.

Puc. 6. $\Rightarrow$

Распределение по федеральным округам приведенного коэффициента развития технологической инфраструктуры

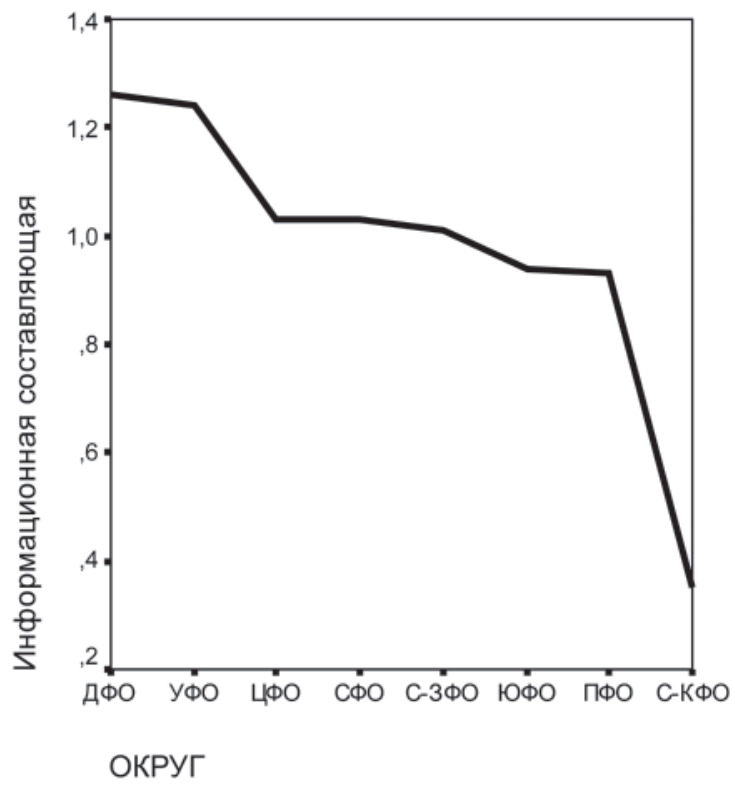

Рис. 5. Распределение по федеральным округам приведенного коэффициента информационной составляющей

Распределение интегрального коэффициента развития технологической инфраструктуры по федеральных округах представлено на рис. 6. Видно, что максимальные значения уровня развития технологической инфраструктуры наблюдаются в Центральном $(1,31)$, Северо-Западном $(1,24)$ и Уральском $(1,15)$ федеральных округах, наименьшие-в Северо-Кавказском (0,29), Дальневосточном $(0,55)$ и Южном $(0,51)$ федеральных округах.

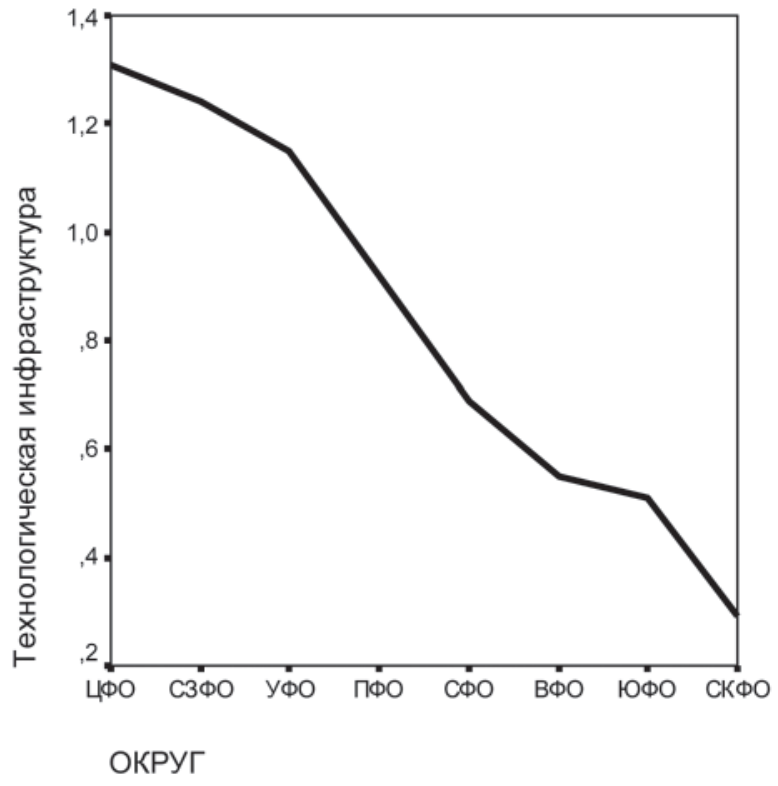


Представленная методика позволяет поэтапно оценить уровень развития технологической инфраструктуры экономических систем, проводить сравнительный анализ внутренней и внешней составляющих инновационной среды, организовать мониторинг и управление развитием экономических систем.

\section{Библиография:}

1. Ивантер В.В. Перспективы и условия инновационно-технологического развития экономики России [Текст] / В.В. Ивантер // Проблемы прогнозирования. 2007. №3. C.3-20.

2. Винокуров В. И. Основные термины и определения в сфере ин-новаций [Текст] / В.И. Винокуров // Инновации. 2005. №4. С.16-18.

3. Мартынов А.Ф. Особенности развития хозяйственных связей в инновационной деятельности регионов [Текст] / А.Ф. Мартынов // Средне-русский вестник общественных наук. 2012. №3. С.227-230.
4. Каменский А.Н. Формирование инновационной инфраструктуры как фактор развития социально-экономических систем [Текст] / А.Н. Каменский // Транспортное дело России. 2010. №12. С.75-79.

\section{References (transliteration):}

1. Ivanter V.V. Perspektivy i usloviya innovacionno-tehnologicheskogo razvitiya ekonomiki Rossii [Tekst] / V.V. Ivanter // Problemy prognozirovaniya. 2007. №3. C.3-20.

2. Vinokurov V. I. Osnovnye terminy i opredeleniya $v$ sfere in-novaciy [Tekst] / V.I. Vinokurov // Innovacii. 2005. №4. S.16-18.

3. Martynov A.F. Osobennosti razvitiya hozyaystvennyh svyazey $\mathrm{v}$ innovacionnoy deyatel'nosti regionov [Tekst] / A.F. Martynov // Sredne-russkiy vestnik obschestvennyh nauk. 2012. №3. S.227-230.

4. Kamenskiy A.N. Formirovanie innovacionnoy infrastruktury kak faktor razvitiya social'noekonomicheskih sistem [Tekst] / A.N. Kamenskiy // Transportnoe delo Rossii. 2010. №12. S.75-79. 